\title{
The SAMR Model as a Framework for Evaluating mLearning
}

\author{
Danae Romrell \\ Lisa C. Kidder \\ Emma Wood \\ Idaho State University
}

\begin{abstract}
As mobile devices become more prominent in the lives of students, the use of mobile devices has the potential to transform learning. Mobile learning, or mLearning, is defined as learning that is personalized, situated, and connected through the use of a mobile device. As mLearning activities are developed, there is a need for a framework within which mLearning activities can be evaluated. The SAMR Model provides such a framework (Puentedura, 2013). This paper reviews recent literature on mLearning and provides examples of activities that fall within each of the four classifications of the SAMR Model: substitution, augmentation, modification, and redefinition.
\end{abstract}

\section{INTRODUCTION}

The SAMR Model as a Framework for Evaluating mLearning With the predominance of mobile devices in our lives, it is natural for educators to ask how they could be used to support learning. In exploring the possibilities and reviewing the research, it becomes clear that there are many factors that influence the implementation of mobile devices within the educational context. Discussions of mobile learning, or mLearning, often focus on selecting an appropriate mobile device for the learning activity in question. However, it is more important for educators and instructional designers to focus on how mobile devices can be used to improve learning. Often, mobile devices are simply used to perform the same tasks that were previously completed without the use of a mobile device. This level of implementation represents the lowest level on the SAMR model, which includes four levels of technology integration (substitution, augmentation, modification, and redefinition) and provides a framework to support educators and instructional designers in creating optimal learning experiences using mobile devices in education. This paper presents a definition of mLearning and recommends the SAMR model as a framework for evaluating mLearning, facilitating the design of mLearning activities, and supporting a transformation of learning. 


\section{METHODS}

What is mLearning? Before research related to mLearning can be discussed, mLearning must be defined. Currently, researchers do not agree on a single definition of mLearning. While there is a mobile device at the heart of mLearning, it is what that device enables teachers and learners to do that truly defines mLearning. A review of the literature on mobile devices in higher education coursework illustrated several unique characteristics of learning with a mobile device that helped us formulate the proposed definition of mLearning. In particular, mobile devices are personal and personalized. They are situated across contexts and time. And they are connected to information, people, and practices. These three characteristics of mobile devices make mLearning unique and different from other types of eLearning. Thus, the proposed definition of mLearning used in this paper is learning that is personalized, situated, and connected through the use of a mobile device (see Figure 1).

\section{mLearning}

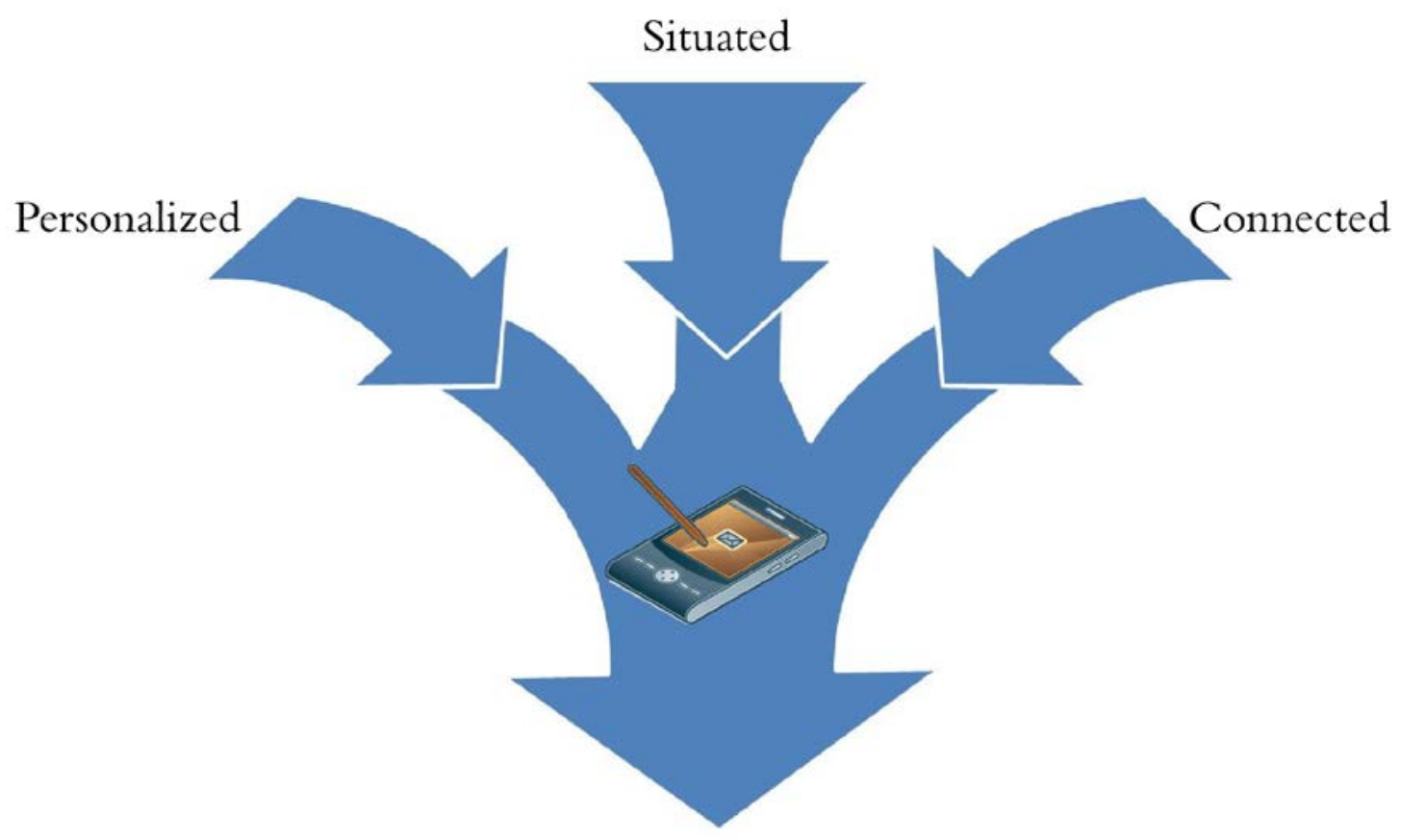

Learning

Figure 1. mLearning is learning that is personalized, situated, and connected through the use of a mobile device. 
Mobile devices. At the center of mLearning is a mobile device. There are many types of mobile devices, including phones, smartphones, tablets, and even small laptop computers. These devices change rapidly, with users purchasing new ones for a variety of reasons, most of them not related to education (Traxler, 2010). In the context of higher education, studies have looked at various tools and applications available on mobile devices. For example, studies have examined the use of podcasts (Cochrane, 2012; Evans, 2008); the use of short messaging systems (SMS), or texting (Brett, 2008; Chuang \& Tsao, 2013; Cornelius \& Marston, 2009; Grönlund \& Islam, 2010); the use of specially designed mobile applications (Dyson, Litchfield, Lawrence, Raban, \& Leijdekkers, 2009; Huang, Jang, Machtmes, \& Deggs, 2012; Lan, Tsai, Yang, \& Hung, 2012; Pfeiffer, Gemballa, Jarodzka, Scheiter, \& Gerjets, 2009; Redondo, Fonseca, Sánchez, \& Navarro, 2013; Wu, Hwang, Su, \& Huang, 2012); the use of the Global Positioning System (GPS) (Liu \& Tsai, 2013); the use of social media applications (Wang, Yu, \&Wu, 2013); and collecting data using images, video, or audio (Cochrane, 2010, 2012; Dyson et al., 2009; Gromik, 2012).

Traxler (2010) stated that "mobile devices, especially connected devices, enable students to consumethat is, to access and store-all sorts of knowledge almost instantly and almost wherever they are, with little or no effort compared with earlier technologies” (p. 154). In the current information age, the ability to access information is an important skill. However, learning is more than the consumption of information, and the research shows that the potential of mobile devices surpasses enabling the simple information-consumption mode. Moreover, there are three key characteristics that identify mLearning as a distinct form of eLearning with unique problems for educators and instructional designers.

Mobile devices are personal. Several researchers have identified personalization as one of the key characteristics of mLearning - for example, Kukulska-Hulme (2009) and Kearney, Schuck, Burden, and Aubusson (2012). A mobile device can be personalized through the addition of unique cases, backgrounds, sounds, and software. As Traxler (2010) observed, "These devices are personal, universal, and closely linked to identity" (p. 152). Looking across a classroom, an instructor can see the personalities of students reflected not only in their choice of mobile device (smartphone, tablet, cellphone) but also in the personalization of the colors, fonts, apps, and accessories associated with their devices.

The familiarity that the learner has with mobile devices impacts how they are used. There is a difference between devices that are borrowed and those that are owned (Kukulska-Hulme, 2009). Owned devices not only reflect the personality and preferences of an individual but also influence their actions, as afforded or hindered by the mobile device. Borrowed devices are less familiar to the owner, which often makes the device harder for the learner to use and makes the learning feel less personal.

Not only can a mobile device itself be personalized, but the learning that occurs on a mobile device can also be personalized. Mobile Web 2.0 tools allow for the personalization of content and interfaces used on the mobile device (Cochrane, 2010). While the personal nature of the device might suggest the usefulness of personalized learning, in some cases the personal nature of the device can be an obstacle in implementing mLearning. Cochrane (2010) found that at times disconnect occurs when students use their personal mobile phones in education. In spite of this potential obstacle, mobile devices allow for both the device and the content to be personalized to the learner. This is the first characteristic that identifies mLearning - it is personalized. 
Mobile devices are situated. Due to their size, mobile devices are portable, making it easy to take them out of the classroom (Cheon, Lee, Crooks, \& Song, 2012). This portability points to the fact that not only are the devices mobile, so are the individuals using them, which allows for learning to be situated within a real-world setting and provides context sensitivity (Cheon et al., 2012). As students move through their daily routines with a device within an arm's reach, they have access to just-in-time information that is situated in the context of their lives. This timeliness of information availability creates opportunities for "new ways of dividing up one's time and crossing boundaries” (Kukulska-Hulme, 2009, p. 153).

There is a constant tension between the formal environment of education and the informal context outside traditional education. Mobile devices enable learning to come to an individual regardless of time or location (Cornelius, Marston, \& Gemmell, 2011; Pfeiffer et al., 2009). mLearning provides an opportunity to create a bridge between formal and informal learning in order to create authentic situated contexts (Cochrane, 2012; Pfeiffer et al., 2009; Traxler, 2010). This is the second characteristic that identifies mLearning - it is situated.

Mobile devices are connected. Cheon et al. (2012) noted that one of the advantages of mobile devices is their instant connectivity. Mobile devices allow for instant connectivity by providing users with the ability to access the Internet, view a video, place a phone call, or send a text message. This access to information, people, and practice, creates a community of learners, even if only for a short period of time or within a specific context. This is the third characteristic that identifies mLearning-it is connected.

Learning that is personalized, situated, and connected through the use of a mobile device has the potential to transform learning in ways not previously envisioned. However, this definition of mLearning, while helpful, is not sufficient when designing instruction. As in research, the use of a framework provides boundaries and anchors to learning theory. With regard to mLearning, the SAMR model is a framework that can be used to evaluate how significantly technology has transformed learning.

The SAMR model as a framework for mLearning. Transformational learning activities that are truly personalized, situated, and connected through the use of a mobile device will go beyond merely using a mobile device as a substitute for more traditional tools. The SAMR model provides a framework that can be used to classify and evaluate mLearning activities. Ruben R. Puentedura developed the SAMR model in 2006 as part of his work with the Maine Learning Technologies Initiative (Puentedura, 2006). The model was intended to encourage educators to significantly enhance the quality of education provided via technology in the state of Maine. The SAMR Model consists of the following four classifications of technology use for learning activities:

- Substitution: The technology provides a substitute for other learning activities without functional change.

- Augmentation: The technology provides a substitute for other learning activities but with functional improvements.

- Modification: The technology allows the learning activity to be redesigned.

- Redefinition: The technology allows for the creation of tasks that could not have been done without the use of the technology. 
Learning activities that fall within the substitution and augmentation classifications are said to enhance learning, while learning activities that fall within the modification and redefinition classifications are said to transform learning (Puentedura, 2013).

Although Puentedura developed the SAMR Model as a way to encourage the use of technology generally, Hockly (2013) suggested using the SAMR Model specifically for mLearning within the context of English language teaching (ELT). This model provides a framework for instructional designers to evaluate mLearning activities in order to determine how well they meet the goal of transforming learning through the use of a mobile device. Building upon the suggestions of Hockly (2013), we reviewed and evaluated research studies involving the implementation of mobile devices in higher education across all disciplines using the SAMR model.

In recent years, a significant amount of research has been done that examines the use of mobile devices in higher education. However, not all of the studies provided in this research fit the definition of learning that is personalized, situated, and connected through the use of a mobile device. From within this body of research, examples of research that address each of the four classifications of the SAMR Model are provided (see Table 1, next page) and reviewed in light of the proposed definition of mLearning.

\section{RESULTS}

\section{Applying the SAMR model to recent research.}

Substitution. Substitution is the simplest way to implement mLearning (Hockly, 2013). mLearning examples that fit into this classification are those where the learning activity could have been done without the use of a mobile device. The following discussion describes three such studies in which mobile devices were used to replace activities that are more traditionally done without the use of a mobile device.

Evans (2008) conducted a study in which podcast lectures were used to replace other forms of review at the end of the course and prior to a comprehensive final examination. In this case, podcasts were used as a substitute for other review methods students might have used, such as reviewing from textbooks or course notes. One significant weakness of this study is that it looked only at student perceptions. It would be beneficial to have a follow-up study that compared learning gains between students who reviewed using podcasts and students who reviewed without the podcasts. In spite of this weakness, the author determined that the students found the podcasts to be a very efficient and effective review tool. One of the main reasons students cited for preferring the podcasts to more traditional forms of review was their portability. One fourth of the participants listened to the podcasts while travelling (p. 495). The author also determined that the students were more engaged with the podcasts than they were with a textbook or in a review lecture (p. 496).

Gromik (2012) conducted a study in which the video camera capabilities of cell phones were used to create videos for an English language class. University students were required to create thirteen 30second videos on topics assigned by the teacher. The videos were recorded with their cell phones. The videos were then uploaded, and access was provided to all students in the class so that they could view one another's videos. 
Table 1

SAMR Classification of 10 Recent mLearning Research Studies

\begin{tabular}{|c|c|c|c|}
\hline Substitution & A & M & R \\
\hline $\begin{array}{l}\text { Evans (2008) } \\
\text { “The Effectiveness of } \\
\text { mLearning in the Form } \\
\text { of Podcast Revision } \\
\text { Lectures in Higher } \\
\text { Education” } \\
\text { Gromik (2012) } \\
\text { “Cell Phone Video } \\
\text { Recording Feature as a } \\
\text { Language Learning } \\
\text { Tool: A Case Study } \\
\text { Lan, Tsai, Yang, and } \\
\text { Hung (2012) }\end{array}$ & $\begin{array}{l}\text { Chuang and Tsao } \\
\text { (2013) } \\
\text { “Enhancing Nursing } \\
\text { Students' Medication } \\
\text { Knowledge: The effect } \\
\text { of Learning Materials } \\
\text { Delivered by Short } \\
\text { Message Service” } \\
\text { Pfeiffer et al. (2009) } \\
\text { "Situated Learning in } \\
\text { the Mobile Age: Mobile } \\
\text { Devices on a Field Trip } \\
\text { to the Sea” }\end{array}$ & $\begin{array}{l}\text { Cornelius et al. (2011) } \\
\text { “SMS Text Messaging } \\
\text { for Real-Time } \\
\text { Simulations in Higher } \\
\text { Education” } \\
\text { Wang, Yu, and Wu } \\
\text { (2013) } \\
\text { “Empowering Mobile } \\
\text { Assisted Social e- } \\
\text { Learning: Students” } \\
\text { Expectations and } \\
\text { Perceptions” }\end{array}$ & $\begin{array}{l}\text { Redondo, Fonseca, } \\
\text { Sánchez, and Navarro } \\
\text { (2013) } \\
\text { "New Strategies Using } \\
\text { Handheld Augmented } \\
\text { Reality and Mobile } \\
\text { Learning-Teaching } \\
\text { Methodologies, in }\end{array}$ \\
\hline
\end{tabular}

The purpose of the assignment was to help students practice composing and speaking the English language. The study found that the creation of the videos helped increase the confidence and speed with which students could converse in English. Students who were interviewed noted that they appreciated the ability to use their cell phones anytime and anywhere for this assignment; however, this study is an example in which cell phones were used as a substitute for other more traditional methods. The same assignment could have been done using video cameras or in-class speeches. Other than an increase in convenience, the assignment offers no functional improvement over assignments that could be given without the use of a mobile device.

Another study in which the use of mobile devices was used as a substitution for another learning activity was conducted by Lan et al. (2012). In this study the authors compared two groups, one that participated in asynchronous online discussions using mobile devices and one that participated in asynchronous online discussions without using mobile devices. They determined that the group that used mobile devices produced more valuable (richer, more relevant, more useful, and more readable) course materials. The mobile users also participated more frequently and were more likely to be active, rather than passive, participants in the discussion boards. 
All three of these studies found that substituting mobile learning for other methods of learning was beneficial. In particular, all three studies noted that the mobility of the devices was beneficial because it allowed the students to engage in the activities at times and in places that they could not with more traditional learning. The fact that students were able to connect to course information from outside of the classroom demonstrates the connected nature of mLearning. The Gromik (2012) and Lan et al. (2012) studies also illustrate the personalized nature of mLearning, as the students created video and produced text within the context of the assignments. Overall, the students generally enjoyed using the mobile devices and thought that they provided a positive alternative to other methods of learning.

Augmentation. Examples of mLearning activities at the augmentation level of the SAMR Model go beyond the substitution level in that they provide some type of functional improvement over what could have been achieved with traditional tools. The following two studies describe situations in which mobile devices were used to augment traditional learning tools.

A study conducted by Chuang and Tsao (2013) looked at the use of SMS text messages to help nursing students memorize information about medications. The study divided the participants into two groups. One group received twice-daily text messages about specific medications in addition to the regular classroom lecture. This use of mobile technology could be classified as augmentation because it added a functional improvement to the previous model of only providing lectures or having the students create their own flashcards. The short messages prompted the students to take a moment to connect to the information to assist them in memorizing vital information about medications. The researchers determined that students who received daily text messages showed significantly higher learning gains at one week, two weeks, and four weeks after the conclusion of the unit.

Pfeiffer et al. (2009) used portable DVD players to augment a situated learning context for a marine biology course. During a snorkeling field trip, students were divided into two groups. The first group used a static printed field guide to help identify species of fish they observed while snorkeling. The second group used a portable DVD player that used video, audio, and static screenshots to display the same information provided in the printed field guide. The addition of the video and audio connected the students to reference materials that more closely resembled the fish in their true context, providing a more situated learning experience. The researchers found that the students who used the dynamic field guide via the portable DVD players showed greater learning gains on a posttest than the students who used the static field guide.

Both of these examples show the connected nature of mLearning activities. The text messages and DVD players were used to connect learners to information. Additionally, the Pfeiffer et al. (2009) study provides an example of a situated activity because the portability of the DVD players allowed the learners to use them on-site. Neither of these examples was personalized, though, because each learner received the same information and viewed the same content.

Modification. Although research has provided examples of positive benefits from both substitution and augmentation of learning using mobile devices, Hockly (2013) asserts that it is in modification and redefinition that the true potential of mLearning is fully realized. It is at the modification and redefinition levels that learning is transformed. 
In a case study by Cornelius et al. (2011), mobile devices were used to modify and significantly redesign a flood disaster simulation in an applied geomorphology course. The use of SMS text messages placed the simulation, based on a real-life scenario, in the students' real lives. SMS text messages were sent to all of the students to update them on the events occurring in a simulated flood disaster. After each message, the students had to decide whether to mobilize the flood alert procedures or not and respond via text message. The next text message received by the student depended on his or her response to the previous text. Based on questionnaires and interviews, the researchers found that the students generally enjoyed the activity and felt it successfully helped them appreciate flood prevention measures. The use of SMS text messages allowed the simulation to be redesigned and allowed for real-time decision making by the students. This design provided truly situated learning. Just as in the simulation, in an authentic situation everyday life would be interrupted by flood alerts. Each student participated individually, supporting the personalized nature of the learning experience. The students suggested improving the realism of the simulation by providing more details in the text messages and providing the students with more than two options. The addition of more details, as suggested by the students, would not only improve the realism of the simulation but would also make the mLearning activity more connected. The real-time decision making significantly increased the realism of the simulation and thereby increased the educational value of the activity.

In another example of modification, Wang, Yu, and $\mathrm{Wu}$ (2013) designed a module, eMASE (mobile assisted social e-learning), for a speech and debate course. Within the module, students were required to work in groups. To support group interaction, training was provided on the most commonly used mobile social applications: Facebook, LINE (a social networking site from Japan), WeChat, Google Hangouts, and YouTube. Students were able to practice within each tool, and the training ensured that all the students and the instructor were included on their contact lists. Students reported that they felt the mobile applications improved their learning and were a useful tool. In this study, the use of the apps was optional, as all the tasks could be accomplished through other traditional means of communication, including meeting in person. The addition of the training and prompting students to think about using mobile social apps within the context of their courses, however, illustrates how mobile devices can connect people. The students' freedom to choose whether to use the tools or not also supports the personalized nature of mLearning. One interesting pattern noted by the authors of this study was that the students who were frequent users of the social networking applications appeared to be more confident and engaged in their learning.

Redefinition. The exploratory case study described by Liu and Tsai (2013) provides an example of redefinition of learning using mLearning because learners were able to participate in learning activities that would not have been possible without a mobile device. The authors developed an augmented-reality cell-phone application to help Chinese students learn English. Using GPS to pinpoint the student's location, English language descriptions of the things around that student would be displayed over the image seen through the phone's camera. Based on student essays and reflections on an open-ended questionnaire, the authors found that participants were engaged in the learning scenario and produced meaningful learning and written essays. The authors concluded that the results of the study suggest that augmented-reality mobile learning may increase the effectiveness of language learning. This implementation of mLearning is personalized in that the students chose to use the application, is situated through the use of GPS and location, and is connected to information through the use of the application. 
Redondo, Fonseca, Sánchez, and Navarro (2013) have explored augmented-reality in what they call "geoeLearning” in architectural studies (p. 188). In one case study, students were divided into two groups based on the capabilities of their personal mobile devices. The experimental group used an augmentedreality overlay to view architectural proposals on-site in 3D. The control group used the traditional methods of 2D and 3D drawings. The results indicated that the students in the experimental group were more proficient in adjusting their proposals to fit the proposed site. Over several case studies, Redondo et al. (2013) have found that the students using the 3D augmented-reality overlay are consistently outperforming the control group. This study also illustrates learning that is personalized, situated, and connected. It is personalized with the students' own projects, situated with the overlay view being available on-site, and connected to information using the architectural applications.

While augmented-reality overlays are good examples that fall into the redefinition level of SAMR, Wu, Hwang, Su, and Huang (2012) provided another relevant example in a different setting. They used a "context-aware mobile learning system" to support nursing students in moving from the novice level to the expert level of proficiency in the physical assessment of patients (p. 223). Traditionally, students are provided with printed lists and demonstrations by instructors followed by time to practice with the dummy patients. The mobile system used in this study replaced the printed lists and guided the students through the practice time with real-time feedback and help. The mobile system connected with the dummy patient when the student approached, beginning with the patient's chart. After a baseline evaluation, the system guided the student through a physical assessment, providing adaptive feedback and support based on the student's degree of mastery. As the students practice, the feedback and support information is faded until the student can perform at the level defined by the instructor. Using a pretestposttest design and including the covariate of the pretest, the authors determined that the students using the mobile system exhibited a significant increase in learning achievement. From the learning logs, Wu et al. (2012) reported that the instant, personalized feedback of the mobile system enabled students to practice more than three times the number of operations as students using the traditional format. In looking at the factors of attitude and cognitive load, the mobile system significantly improves student understanding and self-evaluation and significantly lowers cognitive load. This study exemplified the personalized component of the SAMR model through the use of personalized, adaptive feedback. The simulated lab and patients illustrate a truly situated context. And finally, the students were connected not only to the relevant patient information but also to support information based on their correct or incorrect actions.

Connection between SAMR and the mLearning definition. Puentedura (2013) notes that learning activities that lie at the modification and redefinition levels of the SAMR framework can transform learning. It is at these higher levels of the SAMR framework that the full potential of learning via a mobile device is realized (Hockley, 2013). After the ten articles included in this review were classified based on the SAMR framework, each article was reexamined to determine whether the mLearning example was personalized, situated, and/or connected (see Table 2). This analysis revealed that every example at the redefinition level of the SAMR model was personalized, situated, and connected. This was not true of examples at the lower levels of the SAMR framework. If learning activities involving a mobile device are purposefully designed to be personalized, situated, and connected, the resulting mLearning activities have the potential to redefine and transform learning. 
Table 2

The classification of each mLearning example as personalized, situated, and/or connected.

\begin{tabular}{|c|c|c|c|c|}
\hline Classification & Example & Personalized & Situated & Connected \\
\hline S & $\begin{array}{l}\text { Evans (2008) } \\
\text { Gromik (2012) } \\
\text { Lan et al. (2012) }\end{array}$ & • & & $\bullet$ \\
\hline $\begin{array}{l}\text { A } \\
\text { Augmentation }\end{array}$ & $\begin{array}{l}\text { Chuang and Tsao (2013) } \\
\text { Pfeiffer et al. (2009) }\end{array}$ & & $\bullet$ & $\bullet$ \\
\hline $\begin{array}{l}\text { M } \\
\text { Modification }\end{array}$ & $\begin{array}{l}\text { Cornelius et al. (2011) } \\
\text { Wang, Yu, and Wu (2013) }\end{array}$ & $\bullet$ & $\bullet$ & $\bullet$ \\
\hline $\begin{array}{l}\text { R } \\
\text { Redefinition }\end{array}$ & $\begin{array}{l}\text { Liu and Tsai (2013) } \\
\text { Redondo et al. (2013) } \\
\text { Wu et al. (2012) }\end{array}$ & - & - & • \\
\hline
\end{tabular}

Suggestions for instructional designers. As seen in the research examples above, mLearning activities have the potential to transform learning. Well-designed activities will be personal, situated, and connected through a mobile device to modify or redefine how concepts are taught. However, using a mobile device can also introduce a new set of potential problems.

For mLearning activities at the substitution or augmentation level of the SAMR framework, the increase in technological obstacles presented by the use of a mobile device may prove too cumbersome to justify the use of the mobile device. However, for mLearning activities at the modification or redefinition level of the SAMR framework, the increased technological obstacles will most likely be outweighed by the added benefits of mLearning activities. It is still advisable to develop an implementation design that seeks to decrease the barriers that may be created when using mobile devices in higher education.

While all of the studies mentioned in this review found mLearning to be at least as effective as other methods of learning, some mLearning projects are not successfully implemented. Cochrane (2012) noted that many successful projects initially had problems that were corrected in later iterations of the project. Some of the difficulties that arise during the implementation of a new mLearning activity can be avoided if instructional designers consider and analyze three critical areas as part of the instructional design process: (a) technical issues, (b) pedagogical issues, and (c) management issues (Gedik, HanciKarademirci, Kursun, \& Cagiltay, 2012). 
Technical issues. In regard to issues related to mLearning, it is essential to make an appropriate choice of mobile devices and software (Cochrane, 2012). One of the advantages of using mobile technology is that students often already have their own devices. However, allowing students to use their own devices may lead to difficulty ensuring that the design is compatible with all of the different devices (Gedik et al., 2012). Additionally, researchers have found that students often are not as familiar with their mobile device as might be expected (Dyson et al., 2009). Similar to the training provided in the case study by Wang et al. (2013), it may be necessary to help students learn to use certain features of their personal mobile devices. In some situations, students having different devices might support research, such as that done by Redondo et al. (2013) in which they used students' devices to determine whether students were in the control or the experimental group. Alden (2013) suggested providing students with a list of approved devices. This approach limits the number of different devices that would need to be compatible with the mLearning activities while allowing students to have a selection of devices to choose from.

Regardless of whether students use their own devices or if devices are provided for them, the instructional design plan should include provisions for providing appropriate technological support (Cochrane, 2012). Moreover, it is important that technical support is also provided for the faculty involved in the study (Alden, 2013).

Pedagogical issues. Researchers provided several suggestions for addressing pedagogical concerns when designing mLearning. Cochrane (2012) noted that it is essential to have pedagogical integration of the mobile device. If the mLearning activities are not included in the graded assignments and assessments of the course, students are less likely to take full advantage of the learning opportunities they provide. In addition, the instructor of the course should model appropriate use of the mobile device. Brett (2008) noted the importance of providing specific suggestions to students on how to best use the mobile resources. For example, he observed that when sending course content in text messages, over time students often forget that the information is available. Students will often read the message once and then forget about it. Students benefit when the instructor introduces a new mobile technology with "an explanation of its value ... to ensure full learner awareness of the technology and the learning benefits of engagement” (Brett, 2008, p. 13). Providing regular formative feedback will also help the students see the benefit of the mLearning activities (Cochrane, 2012).

Another pedagogical consideration is that not all educational tools work well on mobile technology, and the pedagogical value of a learning object should be weighed against its ease of use on mobile technology. This requires designers to take into account things such as the screen size, available bandwidth, and the processing speed of the mobile device (Gedik et al., 2012).

Management issues. Creating a detailed plan for how the mobile technology will be managed will help avoid potential difficulties. This plan should include determining how information will be communicated among all of the participating parties (Gedik et al., 2012). The connected nature of mLearning makes it most successful when used as part of a supportive learning community (Cochrane, 2012), which requires the ability of members of the learning community to communicate with each other. Another important management consideration is how to manage the costs associated with using mobile technology. Although mobile devices are extremely prevalent, some students do not have a device or do not want to use their device for schoolwork (this is especially true of phones) (Brett, 2008). Alden (2013) recommended that the use of mobile devices by students not be required. Often it is possible to allow 
students to opt out and use a different method of accessing information. For example, Cornelius et al. (2012) provided their students with the option to receive either text messages or e-mails when participating in a flood disaster simulation. This option allowed students who did not have a cell phone or who did not have a text-messaging plan included with their phone to participate in the simulation without incurring any extra cost. However, for mLearning activities at the highest levels of the SAMR model, students who do not have access to mobile devices will miss the greatest benefits of the activity.

\section{DISCUSSION}

The personalized, situated, and connected nature of mLearning provides instructional designers with exciting new instructional strategies to consider. The use of the SAMR framework can assist in decision making when evaluating potential instructional designs that use mobile technologies. At the lower levels of substitution and augmentation, the obstacles of technology, pedagogy, and management may not be worth the learning gains. At the levels of modification and redefinition, however, mobile technologies become integral to the design of the activity and may be worth the potential problems. Nonetheless, instructional designers should carefully consider how to address the technical, pedagogical, and management issues that will arise during the implementation of the mLearning activity.

This review of the literature focused on studies in higher education that used a wide variety of mobile devices. As such, these recommendations may not apply to other learning contexts. The SAMR model, while helpful, is still very subjective. Using the dual lens of the proposed mLearning definition with the SAMR model provided a useful overlap that highlighted the implementation designs most likely to transform learning. It is recommended that other research studies be evaluated using this dual lens. With additional researchers evaluating the studies in this light, perhaps one model that combines SAMR with the mLearning definition would evolve. This model could then be used to guide the design and development of future studies.

Mobile devices provide unique opportunities that allow learning to be personalized, situated, and connected. Instructional designers should take advantage of these unique characteristics of mobile devices as they design mLearning activities. This provides the greatest chance of designing activities that fall at the highest levels of the SAMR framework. The mLearning activities that modify or redefine traditional learning activities have the potential for transforming learning through the use of a mobile device. 


\section{REFERENCES}

Alden, J. (2013). Accommodating mobile learning in college programs. Journal of Asynchronous Learning Networks, 17(1), 109-122. Retrieved from http://sloanconsortium.org/jaln/v17n1/accommodating-mobile-learning-college-programs

Brett, P. (2008). MeLAS mobiles enhancing learning and support final report. JISC. Wolverhampton, UK. Retrieved from http://www.jisc.ac.uk/media/documents/programmes/elearninginnovation/melasfinalreport.pdf

Cheon, J., Lee, S., Crooks, S. M., \& Song, J. (2012). An investigation of mobile learning readiness in higher education based on the theory of planned behavior. Computers \& Education, 59(3), 10541064. doi:10.1016/j.compedu.2012.04.015

Chuang, Y.-H., \& Tsao, C.-W. (2013). Enhancing nursing students' medication knowledge: The effect of learning materials delivered by short message service. Computers \& Education, 61, 168-175. doi:10.1016/j.compedu.2012.09.013

Cochrane, T. D. (2010). Exploring mobile learning success factors. Association for Learning Technology Journal, 18(2), 133-148. doi:10.1080/09687769.2010.494718

Cochrane, T. D. (2012). Secrets of mlearning failures: Confronting reality. Research in Learning Technology, 5 (2012 Conference Proceedings - A confrontation with reality), 123-134. Retrieved from http://www.researchinlearningtechnology.net/index.php/rlt/article/view/19186

Cornelius, S., \& Marston, P. (2009). Towards an understanding of the virtual context in mobile learning. Research in Learning Technology, 17(3), 161-172. doi:10.1080/09687760903247617

Cornelius, S., Marston, P., \& Gemmell, A. (2011). SMS text messaging for real-time simulations in higher education. In J. Traxler \& J. Wishart (Eds.), Making mobile learning work: Case studies of practice (pp. 13-17). Bristol: ES. Retrieved from http://escalate.ac.uk/downloads/8250.pdf

Dyson, L. E., Litchfield, A., Lawrence, E., Raban, R., \& Leijdekkers, P. (2009). Advancing the mlearning research agenda for active, experiential learning: Four case studies. Australasian Journal of Educational Technology, 25(2), 250-267. Retrieved from

http://www.ascilite.org.au/ajet/ajet25/dyson.html

Evans, C. (2008). The effectiveness of m-learning in the form of podcast revision lectures in higher education. Computers \& Education, 50(2), 491-498. doi:10.1016/j.compedu.2007.09.016

Gedik, N., Hanci-Karademirci, A., Kursun, E., \& Cagiltay, K. (2012). Key instructional design issues in a cellular phone-based mobile learning project. Computers \& Education, 58(4), 1149-1159. doi:10.1016/j.compedu.2011.12.002

Gromik, N. (2012). Cell phone video recording feature as a language learning tool: A case study. Computers \& Education, 58(1), 223-230. doi:10.1016/j.compedu.2011.06.013

Grönlund, Å., \& Islam, Y. M. (2010). A mobile e-learning environment for developing countries: The Bangladesh Virtual Interactive Classroom. Information Technology for Development, 16(4), 244259. Retrieved from http://www.tandfonline.com/doi/abs/10.1080/02681101003746490

Hockly, N. (2013). Technology for the language teacher: Mobile learning. ELT Journal, 67(1), 80-84. doi:10.1093/elt/ccs064

Huang, R.-T., Jang, S.-J., Machtmes, K., \& Deggs, D. (2012). Investigating the roles of perceived playfulness, resistance to change and self-management of learning in mobile English learning outcome. British Journal of Educational Technology, 43(6), 1004-1015. Retrieved from http://doi.wiley.com/10.1111/j.1467-8535.2011.01239.x 
Kearney, M., Schuck, S., Burden, K., \& Aubusson, P. (2012). Viewing mobile learning from a pedagogical perspective. Research in Learning Technology, 20(1), 1-17. doi:10.3402/rlt.v20i0/14406

Kukulska-Hulme, A. (2009). Will mobile learning change language learning? ReCALL, 21(02), 157-165. http://dx.doi.org/10.1017/S0958344009000202

Lan, Y.-F., Tsai, P.-W., Yang, S.-H., \& Hung, C.-L. (2012). Comparing the social knowledge construction behavioral patterns of problem-based online asynchronous discussion in e/m-learning environments. Computers \& Education, 59(4), 1122-1135. Retrieved from http://linkinghub.elsevier.com/retrieve/pii/S036013151200125X

Liu, P.-H. E., \& Tsai, M.-K. (2013). Using augmented-reality-based mobile learning material in EFL English composition: An exploratory case study. British Journal of Educational Technology, 44(1), E1-E4. doi:10.1111/j.1467-8535.2012.01302.x

Pfeiffer, V. D. I., Gemballa, S., Jarodzka, H., Scheiter, K., \& Gerjets, P. (2009). Situated learning in the mobile age: Mobile devices on a field trip to the sea. Research in Learning Technology, 17(3), 187199. doi:10.1080/09687760903247666

Puentedura, R. R. (2006, November 28). Transformation, technology, and education in the state of Maine [Web log post]. Retrieved from http://www.hippasus.com/rrpweblog/archives/2006_11.html

Puentedura, R. R. (2013, May 29). SAMR: Moving from enhancement to transformation [Web log post]. Retrieved from http://www.hippasus.com/rrpweblog/archives/000095.html

Redondo, E., Fonseca, D., Sánchez, A., \& Navarro, I. (2013). New strategies using handheld augmented reality and mobile learning-teaching methodologies, in architecture and building engineering degrees. Procedia Computer Science, 25, 52-61. Retrieved from http://www.sciencedirect.com/science/article/pii/S187705091301212X

Traxler, J. (2010). Students and mobile devices. Research in Learning Technology, 18(2), 149-160. doi:10.1080/09687769.2010.492847

Wang, J., Yu, W., \& Wu, E. (2013). Empowering mobile assisted social e-learning: Students' expectations and perceptions. World Journal of Education, 3(2). doi:10.5430/wje.v3n2p59

Wu, P.-H., Hwang, G.-J., Su, L.-H., \& Huang, Y.-M. (2012). A context-aware mobile learning system for supporting cognitive apprenticeships in nursing skills training. Educational Technology \& Society, 15(1), 223-236. Retrieved from http://eric.ed.gov/?id=EJ979517 


\section{Acknowledgements}

We would like to acknowledge Dr. Dotty Sammons of Idaho State University for her suggestions and input on this project.

\section{About the Authors}

Danae Romrell has a background in mathematics and mathematics education. After four years of teaching high school, she has been teaching college-level mathematics for eight years. She is currently a member of the mathematics faculty at Brigham Young University - Idaho as well as a PhD candidate in the Instructional Design program at Idaho State University. Her research interests include multimedia design, online education, mathematics education, and gaming.

Lisa Kidder has 20 years of experience in teaching and learning with technology. She currently works in the Instructional Technology Resource Center at Idaho State University. With a background in French, chemistry, and educational technology in both $\mathrm{K}-12$ and higher education, she brings a wealth of experiences to conversations on best teaching practices using technology. Her research interests are in online delivery, faculty development, and visual design.

Emma Wood has a background in special education, specifically deaf education. She has taught in Teacher Education at Idaho State University for the past five years. Emma is also the Instructional Technology Coordinator for the College of Education. Currently a PhD Candidate in Instructional Design, her research interests include underprepared students, Universal Design for Learning, and Self-Directed Learning skills. 